\title{
WarpPLS emulator for macOS
}

Dao Duy Tung

Tay Do University, Vietnam

\section{Introduction}

Windows programs which don't have a dedicated version for Mac OS X cannot be ran on Mac directly, but they can be ran with the help of a special tool. There are two basic ways to run Windows programs on a Mac. One is emulation, and another is virtualization. Emulation refers to simulating the basic portions of the Windows environment necessary to run some Windows programs on a non-Windows system. The most well-known emulator is WINE, which is a humorous acronym for "WINE Is Not an Emulator". While it is possible to build WINE on Mac an official pre-built binary package is not available and building it yourself is probably exceedingly difficult. That's where third party WINE distributions come in. Likely the best among them is PlayOnMac which comes as a standard Mac app and features an easy to use interface with which you can browse and install compatible Windows applications.

PLAYONMAC is a graphical front-end for Wine compatibility layer. It simplifies the installation of Windows apps and (especiall)y games on GNU/Linux by auto-configuring Wine. It provides wrapper shell scripts to specify the configuration of Wine for any particular software. It also uses an online database of scripts to apply for different programs.

\section{Link download at here.}

*Note: PLAYONMAC incompatibility macOS Catalina (10.15) and next, because it dropped 32bits support.

\section{CHANGELOGS}

- Instead of function "DOWNLOAD" to "LOCAL" on my script.

- Fixed error "Wine packages website is unavailable".

- Fixed error "failed download wine 2.20" on PLAYONMAC.

- Woking with multiple versions of WarpPLS.

KNOWN ISSUE

- Does not work with WINE 4.0 -5.0

- $\quad$ Error SSL on PLAYONMAC version 4.4.1 => cannot download wine and connect.

Requirement for WarpPLS installation on Mac

- XQuartz 
In the first time, Mac will verifying PLAYONMAC on Applications when you run it. Once popup shows messages "can not be opened because ...". Just click OK.

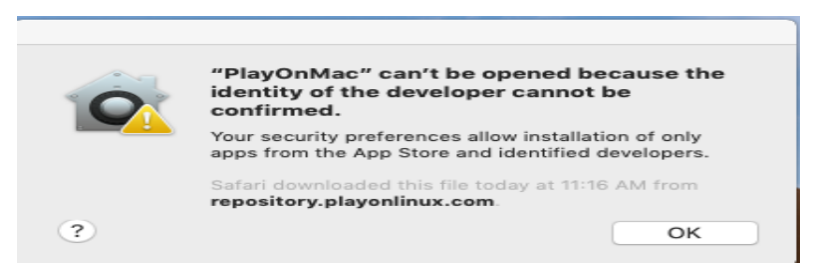

Next, open Security and Privacy, click button "Open anyway"

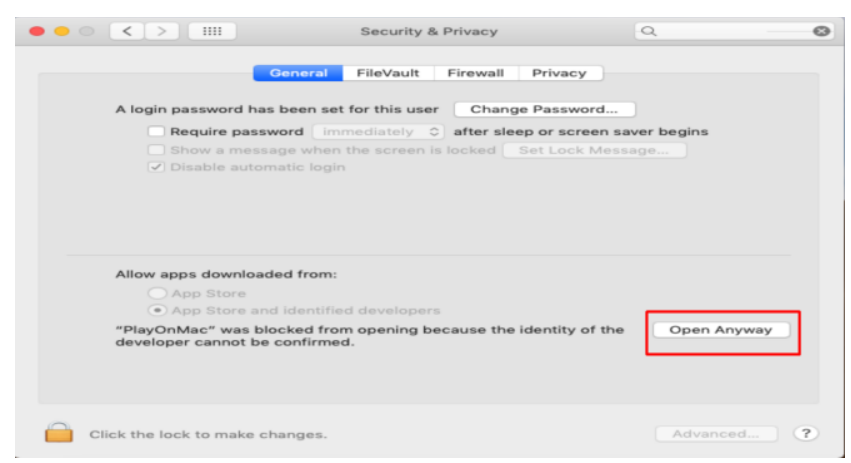

After click button, PLAYONMAC starting and warning "PLAYONMAC will always allow it to run on this Mac." You choose Open. Now, see continous pages for installation WarpPLS.

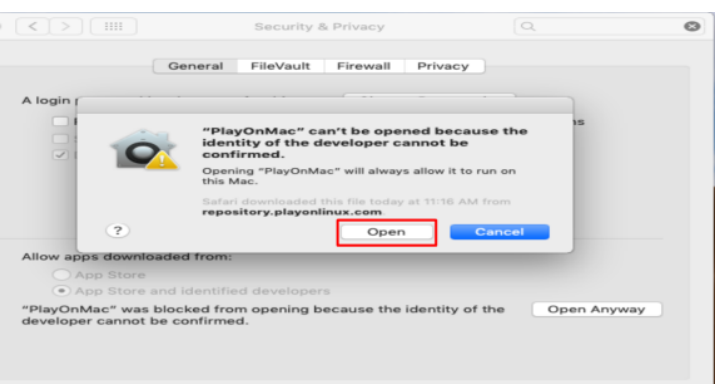


Step 1: Click choose Install button/Install a program
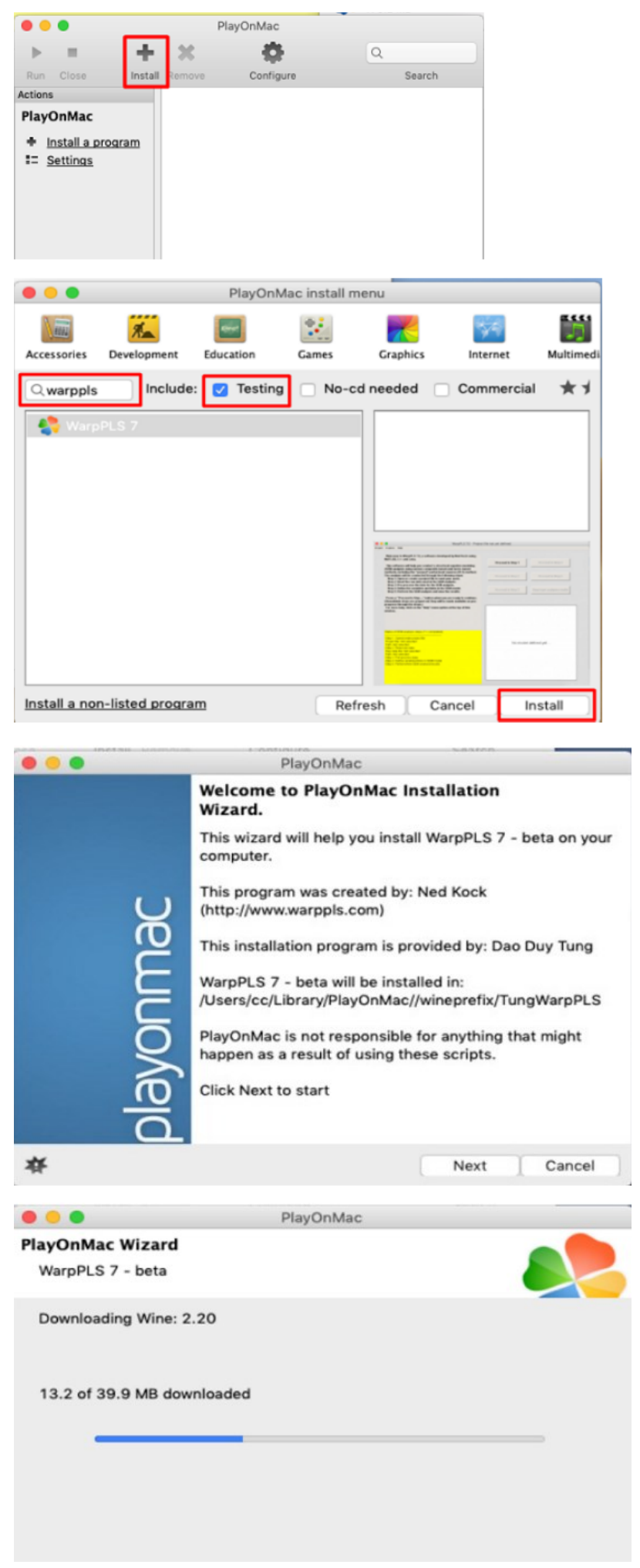
Step 2: Select existing file

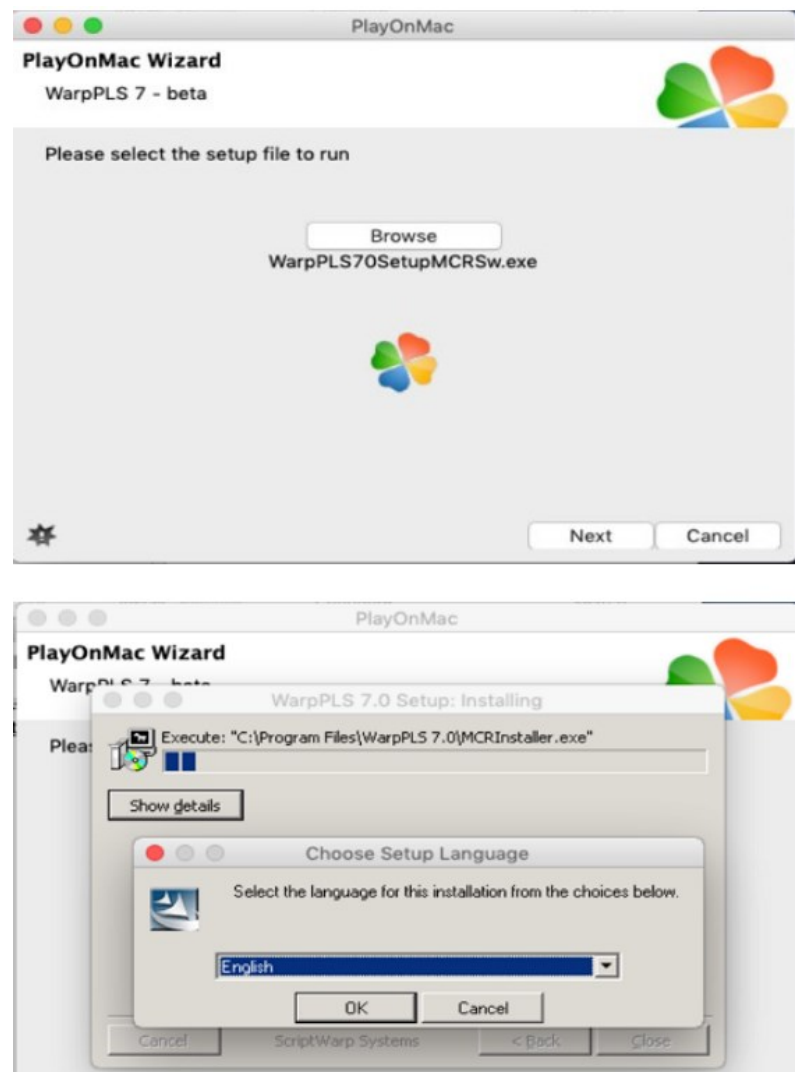

Step 3: Run shortcut on desktop
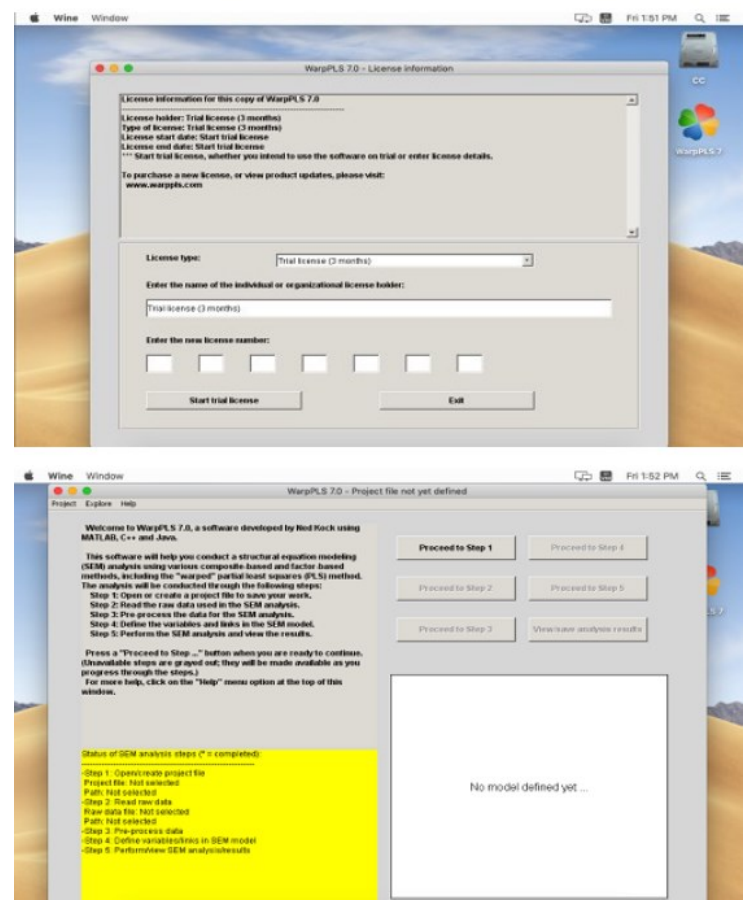